\title{
THE COHYDROLASES IN HUMAN SPLEEN THAT STIMULATE GLUCOSYL CERAMIDE $\beta$-GLUCOSIDASE
}

\author{
SHANKAR S. IYER, SUSAN L. BERENT and NORMAN S. RADIN * \\ Mental Health Research Institute (Department of Psychiatry) and Department of Biological Chemistry, University of Michigan, Ann \\ Arbor, MI 48109 (U.S.A.)
}

(Received May 9th, 1983)

Key words: $\beta$-Glucosidase-stimulating protein; Gaucher disease; Cohydrolase; Sphingolipid; Antibody binding; (Human and bovine spleen)

A family of $\beta$-glucosidase-stimulating proteins (called cohydrolase SPH-I here) was isolated from bovine, Gaucher human and control human spleens. All preparations exhibited a similar pattern of four major electrophoretic bands in polyacrylamide when stained with the cationic dye, Stains-All. The bovine bands migrated more rapidly, while the two types of human cohydrolase migrated very similarly. The two human preparations differed in several respects: the concentration was much higher in Gaucher spleen; the Gaucher factors eluted a little earlier from gel permeation and decyl agarose columns; much more of the cohydrolase was bound by a concanavalin $A$ column; the control bands stained less intensely in gels than the Gaucher bands. Antibodies raised in rabbits to bovine cohydrolase reacted with all three preparations. All four bands from Gaucher cohydrolase showed similar ability to stimulate glucosidase and to bind the antibodies. It is evident that the cohydrolases from control and Gaucher spleens are similar in many respects, yet differ in some secondary fashion, possibly in carbohydrate content. It is suggested that Gaucher cohydrolase is formed from normal cohydrolase by the nonenzymatic action of cellular glucose over a period of many years, due to slowed catabolism of the cofactor.

\section{Introduction}

A class of proteins exists having the ability to act in coordination with or to stimulate various hydrolases. The best-studied protein in this group is colipase, which acts with pancreatic lipase [1]. In extension of this name, we suggest the generic term, cohydrolase, with appropriate suffixes to identify the substrate.

Ho and O'Brien [2] described a preparation from Gaucher spleen which stimulated hydrolysis of an artificial $\beta$-glucoside. The preparation also

\footnotetext{
* To whom correspondence should be addressed at: $1103 \mathrm{E}$. Huron, Ann Arbor, MI 48109, U.S.A.
}

stimulated the hydrolysis of the naturally occurring $\beta$-glucoside, glucosyl ceramide [3]. We have obtained a highly purified material having similar properties from normal bovine spleen [4,5]. Later work, with this and a preparation from human spleen, showed that it can also stimulate the sphingolipid hydrolases, cerebroside $\beta$-galactosidase and sphingomyelinase [6,7]. In this case, the factor could be called cohydrolase SPH-I (where SPH refers to sphingolipids and the I refers to the fact that other sphingolipid cohydrolases exist).

Polyacrylamide electrophoresis of bovine cohydrolase in cylindrical gels showed the presence of a small amount of fast-moving activator and a slightly slower major component moving as a wide band, with some signs of heterogeneity [4]. 
The activator could be eluted from slices of the major band as fractions having similar specific activity throughout the band. The cofactor was also shown to bind to the enzyme, not to the substrate [8] and, indeed, the human [9] and bovine [8] cohydrolases could be immobilized in a column packing and used as an affinity medium for enzyme purification.

Patients with Gaucher disease suffer from a genetic lack of glucosyl ceramide glucosidase activity, so a large amount of the substrate accumulates in their tissues, especially in spleen and liver [10]. In addition, cohydrolase SPH-I activity also accumulates in the spleen $[2,11]$. It was suggested [12] that the accumulation is due to the presence of a $\beta$-glucoside moiety in one of the forms of the protein, the glucoprotein being a second substrate for the same glucosidase. This hypothesis presupposes that the glucosyl form of cohydrolase cannot be catabolized without initial removal of the terminal glucose moiety. Support for the idea comes from the report that glucose is indeed present in human cohydrolase [11], but the linkage type is unknown.

Given this hypothesis, one would expect that cohydrolase in normal tissues exists in two forms, one containing glucose, the other not, while in Gaucher tissues one would find primarily the glucosylated form. Indeed, a report on the properties of cohydrolase preparations isolated from control and Gaucher spleen stated that the latter contains much more carbohydrate [11]. However, this report also indicated that they contain quite different protein backbones. This finding is difficult to explain, even if one assumes that two different mutations occur simultaneously in the same patients. It seemed useful to investigate these matters with our new isolation procedure and improved electrophoretic methods.

\section{Materials and Methods}

Isolation of human cohydrolase. The previously described method was used [4,5] but the elution conditions had to be modified for the hydroxyapatite column (see Results). One control spleen was removed surgically from a patient with pancreatic carcinoma, another from a patient with idiopathic thrombocytopenic purpura. One
Gaucher spleen was removed from a 4-year-old, another from an adult.

Electrophoresis. Polyacrylamide slabs, $0.75 \mathrm{~mm}$ thick, $12.5 \times 12.5 \mathrm{~cm}$, were prepared from acrylamide $(16 \%$ in running gel, $2.5 \%$ in stacking gel), $0.2 \%$ Triton X-100, and other components at pH 9 [13]. The samples ( $35 \mu 1,0.2 \%$ Triton, $0.1 \mathrm{M}$ Tris- $\mathrm{HCl}, 10 \%$ sucrose) were added to wells in the stacking gel, previously filled with running buffer (3 g Tris $/ 14.4 \mathrm{~g}$ glycine $/ 2 \mathrm{~g}$ Triton per liter). Alternate wells were left empty. Electrophoresis was carried out at $4 \mathrm{~W}$ for $5 \mathrm{~h}$.

In initial tests, bromphenol blue was included in the samples and the separation was stopped when the indicator reached the bottom $(4 \mathrm{~h})$. However, to improve the separations we increased the run time an additional hour.

The slabs were stained overnight with $0.025 \%$ Stains-All [14] and destained with water overnight, protected from light. This useful cationic carbocyanine dye, which has been found to produce blue bands with DNA, RNA and acidic proteins, yielded bright blue bands with cohydrolase, pinkish purple with ovalbumin, greenish blue with soybean trypsin inhibitor, and dark purple with egg white phosvitin. The latter proteins were included in one of the wells as a check on the quality of the run.

Recovery of cohydrolase from gels. Stained slabs were sliced with a razor blade and the bands were homogenized in the same eluent that was used for the decyl agarose column: $5 \mathrm{mM}$ sodium phos-

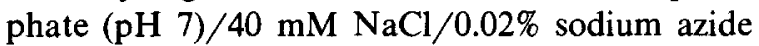
(buffer A) in ethylene glycol/water 9:1, using 6.7 $\mathrm{ml} / \mathrm{cm}^{2}$ of gel. The suspension was shaken $30 \mathrm{~min}$ and centrifuged, and the pellet was re-extracted twice more as above, but with half the volume of buffer. The dye in the extract was removed by passing the solution through a column of Sephadex G-15 $(1.26 \times 12 \mathrm{~cm})$ and eluting with buffer A containing $0.1 \%$ Triton.

Protein determination. This was done with a combination of methods [15-17] needed for the precipitation of glycoprotein in the presence of Triton. Each sample $(0.7 \mathrm{ml})$ from the recovered protein in each band was treated with $0.2 \mathrm{ml}$ of $10 \% \mathrm{SDS}, 30 \mu \mathrm{l}$ of yeast S-RNA $(5 \mathrm{mg} / \mathrm{ml})$ and 1 $\mathrm{ml}$ of $10 \%$ trichloroacetic acid/1\% phosphotungstic acid. The resultant pellet was dissolved in 0.8 $\mathrm{ml}$ of a copper reagent containing SDS and as- 
sayed with $0.2 \mathrm{ml}$ of Folin reagent.

Cohydrolase assay. The activator was measured with a stock preparation of glucosidase, using methylumbelliferyl glucoside as substrate $[4,5]$. One activity unit corresponds to a $50 \%$ stimulation.

Immunological methods. New Zealand White rabbits were injected intradermally in 25-30 sites, each with $25 \mu 1$ of a homogenate made from $0.5 \mathrm{ml}$ $(0.55 \mathrm{mg})$ bovine cohydrolase, $0.25 \mathrm{ml}(1.1 \mathrm{mg})$ of carboxymethylated bovine serum albumin (Aldrich Chemical, Milwaukee, WI), and $1.5 \mathrm{ml}$ of Freund's complete adjuvant (Difco Labs., Detroit, MI). Methylated albumin, a basic protein, was used, since it forms a salt complex with cohydrolase, an acidic material. The immunization was repeated 10 and 24 weeks later. Blood was drawn at 2-week intervals and the serum was stored at $-20^{\circ} \mathrm{C}$. Before use, each sample was heated at $56^{\circ} \mathrm{C}$ for $20 \mathrm{~min}$ and clarified by centrifugation. Dilutions were made with buffer $\mathrm{A}$.

The cohydrolase/serum reaction was evaluated by the double antibody, enzyme-linked method [18] in polystyrene microtitre wells (Nunc-Immuno Plate I, Vangard Intl., Neptune, NJ). The wells were coated by adding $25 \mu 1$ ( $25 \mathrm{ng}$ ) of cohydrolase in buffer A, then $75 \mu \mathrm{l}$ of buffer A. (This avoided storing cohydrolase in too dilute a solution.) Almost all the cohydrolase was adsorbed by the wells within $16 \mathrm{~h}$ at $25^{\circ} \mathrm{C}$. The wells were washed with buffer $\mathrm{A}$, filled with blocking solution $(0.1 \%$ human serum albumin in $1.2 \% \mathrm{NaCl})$, and left for $5 \mathrm{~min}$. (Human albumin was used rather than bovine, since the immunizing suspension had included methylated bovine albumin and the rabbit serum was likely to contain antibodies to the latter.)

After the plates had been shaken dry, $50 \mu 1$ of diluted antiserum were added and incubated $12 \mathrm{~h}$ at room temperature. The wells were next washed with $0.02 \%$ Tween 20 in $1.2 \% \mathrm{NaCl}$ and with $1.2 \%$ $\mathrm{NaCl}$. The bound rabbit immunoglobulins were then reacted with $50 \mu 1$ of peroxidase-linked affinity-purified antibodies against rabbit $\operatorname{IgG}(\mathrm{H}+\mathrm{L})$, prepared in goats (Kirkegaard and Perry Labs., Gaithersburg, MD), diluted with $10 \mathrm{mM}$ sodium phosphate $(\mathrm{pH} 7) / 1 \%$ human serum albumin/ $1.2 \% \mathrm{NaCl}$. After allowing $60 \mathrm{~min}$ for binding, we washed the plates as above, then rinsed the wells with $1.2 \% \mathrm{NaCl}$ prepared in water sold for high- performance liquid chromatography, to prevent inhibition of the peroxidase. The amount of peroxidase bound to the wells was determined with a chromogenic substrate [18] by incubation for $14 \mathrm{~h}$ at room temperature, followed by quantitation with an automatic plate reader (Titertek Multiskan, Flow Labs., Inglewood, CA).

\section{Results}

\section{Chromatographic isolation of cohydrolases}

As in the method for isolating bovine cohydrolase [4], the steps involved scraping the pulp from thawed spleen, homogenization, adjustment to $\mathrm{pH}$ 6 , heat treatment, batch uptake on DEAE-Sephacel, and chromatography on columns of DEAE-Sephacel, Sephadex G-75, hydroxyapatite and decyl agarose. In the case of the hydroxyapatite column, human cohydrolase eluted later than expected, so the phosphate buffer gradient was changed to a much steeper slope: 5 to 400 $\mathrm{mM}$.

Control and Gaucher spleens differed not only with respect to the well-known difference in size but also with respect to the yield of scraped pulp. The Gaucher spleen yields were $77 \%$ and $88 \%$ of the spleen weight, while the control yields were 94\% and $97 \%$.

The Gaucher cohydrolase seemed to have a higher average molecular size, judging by its elution from the Sephadex column. With a 500-ml column, the control activator eluted as a single peak starting at $264 \mathrm{ml}$ elution volume, ending at $343 \mathrm{ml}$ and peaking at $304 \mathrm{ml}$. The Gaucher activity appeared earlier $(220 \mathrm{ml})$, ending at 316 $\mathrm{ml}$. It exhibited three severely overlapping but distinct peaks at 228, 251 and $297 \mathrm{ml}$.

The active fractions from the gel permeation column (between 220 and $316 \mathrm{ml}$ ) were pooled and applied to the hydroxyapatite column. Here too the control factor eluted as a single, relatively sharp peak (at the point where the eluent entering the column was $120 \mathrm{mM}$ in phosphate) and the Gaucher factor eluted as several peaks. The first, a relatively small one, came out before the start of the gradient and was discarded. Two additional, overlapping peaks eluted at 100 and $140 \mathrm{mM}$ phosphate and were pooled for the next step.

The next column, $7.85 \mathrm{ml}$ of decyl agarose, was 
operated with a $100 \mathrm{ml}$ gradient of $0-90 \%$ ethylene glycol [4]. The Gaucher activity eluted earlier than the control factor: between $55-128 \mathrm{ml}$ as opposed to $96-124 \mathrm{ml}$. Judging by this difference, Gaucher cohydrolase is more hydrophilic.

One possible explanation for the above differences in elution behavior is that the loads of cohydrolase applied to the columns were so different, since equal weights of tissue were used. The Gaucher spleen was found to yield about 17-times as much cohydrolase as the control. When the isolation was carried out with equal amounts of activity, similar differences between control and Gaucher cohydrolase were seen in the elution profiles.

Data from two runs (Table I) showed that the yields of purified cohydrolase were $2.7 \mu \mathrm{g} / \mathrm{g}$ from control and $47 \mu \mathrm{g} / \mathrm{g}$ from Gaucher spleen. Similar differences in yield and column behavior were seen with the other two spleens studied. An important observation is that both the control and Gaucher preparations had similar specific activities. Bovine cohydrolase, however, showed a somewhat lower specific activity: about 37 vs. 87 units $/ \mu \mathrm{g}$ protein.

An attempt to isolate cohydrolase from a pool of four autopsy spleens yielded no activity at all.

\section{Electrophoretic comparisons}

The pattern found with cohydrolase from control spleen was remarkably similar to that found with Gaucher cohydrolase (Fig. 1). However, when the Gaucher sample was applied to the gel at high loads, an appreciable amount of trailing material

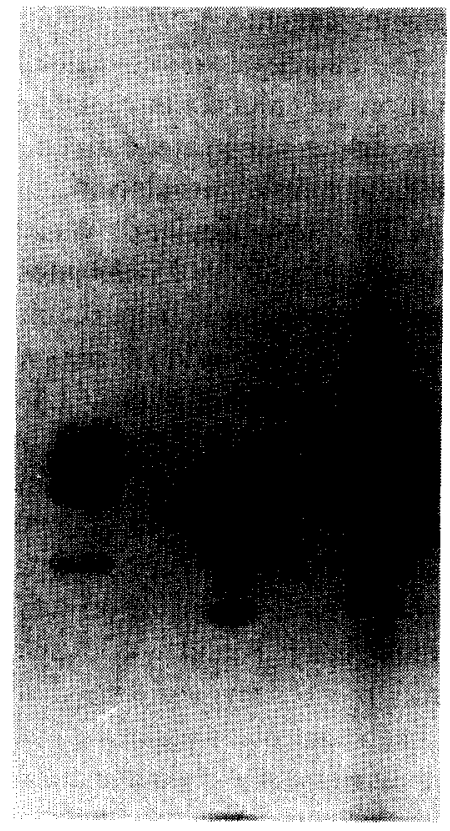

Fig. 1. Polyacrylamide gel electrophoretogram of cohydrolases SPH-I $(12.5 \mu \mathrm{g})$, run in alkaline buffer, stained with Stains-All. Left lane, control human; center lane, bovine; right lane, Gaucher spleen.

was seen, staining the same characteristic color. When equal weights of protein were applied, the bands from Gaucher cohydrolase stained distinctly more intensely. Bovine cohydrolase also exhibited the same pattern (one fast band and a cluster of three slower ones), but its migration rate was higher.

The major bands from a Gaucher sample were

TABLE I

PURIFICATION OF COHYDROLASE FROM CONTROL AND GAUCHER HUMAN SPLEENS

\begin{tabular}{|c|c|c|c|c|c|c|}
\hline \multirow[t]{2}{*}{ Step } & \multicolumn{3}{|c|}{ Control spleen $(150 \mathrm{~g}, 132 \mathrm{~g}$ pulp $)$} & \multicolumn{3}{|c|}{ Gaucher spleen ( $530 \mathrm{~g} .500 \mathrm{~g}$ pulp) } \\
\hline & $\begin{array}{l}\text { Total } \\
\text { protein } \\
\text { (mg) }\end{array}$ & $\begin{array}{l}\text { Total } \\
\text { activity } \\
\text { (units } \times 10^{-3} \text { ) }\end{array}$ & $\begin{array}{l}\text { Spec. } \\
\text { act. } \\
\text { (units } / \mu \mathrm{g} \text { ) }\end{array}$ & $\begin{array}{l}\text { Total } \\
\text { protein } \\
(\mathrm{mg})\end{array}$ & $\begin{array}{l}\text { Total } \\
\text { activity } \\
\text { (units } \times 10^{-3} \text { ) }\end{array}$ & $\begin{array}{l}\text { Spec. } \\
\text { act. } \\
\text { (units } / \mu \mathrm{g} \text { ) }\end{array}$ \\
\hline 1. pH 6 homogenate & 9340 & & & 21800 & & \\
\hline 2. Heated supernatant & 2250 & & . & 11800 & & \\
\hline 3. Released from DEAE-Sephacel & 188 & & & 340 & & \\
\hline 4. DEAE-Sephacel columns & 66 & 73 & 1.1 & 116 & 1114 & 9.6 \\
\hline 5. Sephadex G-75 & 12 & 66 & 5.7 & 67 & 1230 & 18.5 \\
\hline 6. Hydroxyapatite & 2 & 121 & 67 & 37 & 1870 & 50 \\
\hline 7. Decyl agarose & 0.4 & 37 & 92 & 25 & 2009 & 81 \\
\hline
\end{tabular}


TABLE II

GLUCOSIDASE-STIMULATING ACTIVITY OF INDIVIDUAL COHYDROLASE BANDS

Specific activity was assayed in the presence of buffer A. Band $A$ is the slowest band, $D$ is the fastest.

\begin{tabular}{llll}
\hline Sample & $\begin{array}{l}\text { Protein } \\
\text { content } \\
(\mu \mathrm{g})\end{array}$ & $\begin{array}{l}\text { Activity } \\
\text { per sample } \\
\text { (units) }\end{array}$ & $\begin{array}{l}\text { Spec. act. } \\
\text { (units } / \mu \mathrm{g})\end{array}$ \\
\hline Original & & & \\
$\quad$ mixture & $840^{\mathrm{a}}$ & $50000^{\mathrm{a}}$ & 59 \\
Band A & 177 & 8890 & 50 \\
Band B & 135 & 6400 & 48 \\
Band C & 80 & 4000 & 50 \\
Band D & 80 & 5000 & 63 \\
Slow trail & 46 & 2180 & 48 \\
\hline
\end{tabular}

a Amount of Gaucher cohydrolase applied to acrylamide gels.

eluted and assayed for activity and protein (Table II). The yield of protein obtained on elution was $62 \%$ and the yield of stimulating activity was almost the same, 53\%. An important feature of the findings is that the specific activities of all the bands, including the diffuse trailing material, were quite similar.

\section{Immunological comparisons}

The antisera raised against bovine cohydrolase yielded the usual titration curves with titre plates coated with the bovine preparation. A study of the time needed for binding the immunoglobulins to the factor showed that the process was a little slow, $12 \mathrm{~h}$ giving maximal readings. Longer reaction times yielded lower titres, possibly because the cohydrolase-antibody complex dissociated from the plastic surface. The titres for various serum samples ranged between $1: 2000$ and $1: 12000$ for half-maximal readings, while control sera from the same animals yielded titres of about $1: 240$. The rabbits, with some booster injections, have been producing antibodies for almost two years and the antibodies have been purified by an affinity column containing cohydrolase for development of an immunoassay.

An important finding was that both human cohydrolases reacted with the bovine-induced antisera. The titres, measured with a single serum, were 1:8000 for bovine, 1:4000 for control human, and 1:4500 for Gaucher cohydrolase. In addition, the proteins extracted from the electrophoretic bands all reacted with the antisera, giving titres of $1: 4500$ to $1: 3500$.

Attempts were made to assay cohydrolase by using antibodies to block its stimulatory action on glucosidase. The most potent antiserum, diluted $1: 1280$ to $1: 5120$, was incubated with $10-40 \mathrm{ng}$ of bovine cohydrolase in buffer $A$ for 2 or $6 \mathrm{~h}$ at $37^{\circ} \mathrm{C}$. Glucosidase, Triton and substrate were then added and incubated in the usual way. Cohydrolase incubated without antibodies showed a $15-20 \%$ loss in activity (compared with freshly added cohydrolase) and the antibodies prevented this loss. Possibly the incubation pH (4.5) caused dissociation of the antigen/antibody complex.

\section{Concanavalin $A$ affinity column}

Since previous analyses $[2,4,11]$ had indicated the presence of carbohydrate in human and bovine cohydrolase, and the bovine electrophoretic band had reacted positively with a glycoprotein stain, we passed $92 \mu \mathrm{g}$ of the purified control and Gaucher factors through a column of Con A-Sepharose $(0.7 \times 2.5 \mathrm{~cm}$, Sigma Chemical Co. $)$ equilibrated with buffer $\mathrm{A}$ made from $0.5 \mathrm{M} \mathrm{NaCl}$. After the samples were added, in the same buffer, elution was carried out with $14 \mathrm{ml}$ of buffer at 8 $\mathrm{ml} / \mathrm{h}$, followed by $8 \mathrm{ml}$ of the buffer augmented with $0.5 \mathrm{M}$ methyl $\alpha$-mannoside. The active frac-

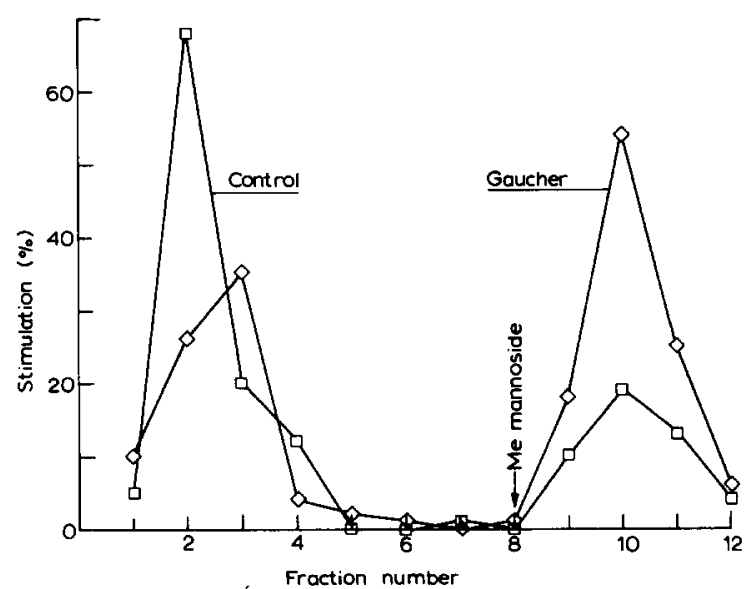

Fig. 2. Chromatographic fractionation of human cohydrolases with a column of Sepharose-bound concanavalin A. The fractions ( $2 \mathrm{ml}$ each) were assayed for ability to stimulate glucosidase. The first peak represents the unbound fraction; the second, the bound fraction released by methyl mannoside. 
tions were pooled and concentrated while dialyzing against buffer $A$, using a pressurized ultrafiltration device (Micro-ProDiCon, Bio-Molecular Dynamics, Beaverton, OR).

It was found (Fig. 2) that part of the cohydrolase activity adhered to the column, and that the proportion eluted by methyl mannoside was much greater for the Gaucher factor. While the yields of protein from this step were only $56 \%$ for the control protein and $87 \%$ for the Gaucher protein, the yields of cohydrolase activity were $102 \%$ and $130 \%$, respectively. The specific activities of the Con A binding material were 190 and 166 units $/ \mu \mathrm{g}$, for the control and Gaucher samples.

Electrophoresis of the bound and unbound pro-



Fig. 3. Electrophoretogram of the human cohydrolase fractions that were separated by the concanavalin A column (see Fig. 2). Lane 1, bound Gaucher (10 $\mu \mathrm{g}$ ); lane 2, unbound Gaucher ( 9 $\mu \mathrm{g})$; lane 3 , bound control ( $6 \mu \mathrm{g})$; lane 4 , unbound control (9 $\mu \mathrm{g})$; lane 5 , total Gaucher cohydrolase, before addition to column $(12.5 \mu \mathrm{g})$; lane 6 , total control cohydrolase $(12.5 \mu \mathrm{g})$. In the gel shown here, a slightly unusual method was used in order to reduce the problem of trailing band edges. After polymerizing the running gel, we poured the stacking gel solution only up to the bottoms of the wells. After this had polymerized, we cast running gel (16\% acrylamide) around the well-forming comb. This technique, which greatly reduces the diffusion of small protein molecules during the setting-up steps, proved distinctly helpful. teins (Fig. 3) showed that the former consisted primarily of bands $A$ and $B$, the two slowest migrating components. The nonbinding cohydrolase was seen to consist of bands $C$ and $D$, but distinct amounts of $\mathrm{A}$ and $\mathrm{B}$ were also visible in the material from control spleen.

\section{Discussion}

While the chromatographic data point to distinct differences between cohydrolases from control and Gaucher spleens, the other results electrophoretic migration pattern and staining, and immunological similarity - suggest that the two groups of proteins are indeed very similar. Some of the chromatographic differences may be due to differences in the relative proportions of the different 'iso-cohydrolases,' which were partially separated by the columns. However, the relative intensities of the stained electrophoretic bands looked very similar to the eye.

The previous report [11] that Gaucher and control cohydrolases were very different with respect to amino acid composition may have arisen from the presence of a significant amount of contaminating proteins, since cohydrolase stains so poorly with the common protein stains [4].

Many of our observations could be explained by a small modification of the hypothesis offered before [12] and in the Introduction. This is the idea that a single protein backbone accounts for all the forms of cohydrolase and that the separate bands are due to small differences in the backbone, such as differences in amidation or small deletions in the peptide chain, presumably made by posttranslational protein-processing enzymes. The differences between Gaucher and control cohydrolases can then be ascribed to differences in the carbohydrate side-chains.

These differences could be attributed to the presence of $\beta$-linked glucose moieties attached to the terminal position of polysaccharide sidegroups. The glucose moieties are ordinarily removed during catabolism of the activators. In people with Gaucher disease, the deficiency in $\beta$-glucosidase would cause accumulation of the glucosylated form, with the consequent differences we observed in chromatographic behavior (higher molecular weight, weaker binding to the lipophilic 
column packing, binding to Con A, and - perhaps - the stronger staining with Stains-All). The enhanced binding to Con $A$ is presumably due to mannoside linkages inside the glucose-terminated oligosaccharide groups.

A second hypothesis could explain the observed differences between Gaucher and control proteins. It is now known that many proteins react nonenzymatically, at a slow but steady rate, with the glucose that is normally present in cells and plasma $[19,20]$. The glucose reacts with some of the free amino groups, forming a Schiff base which gradually rearranges to form a more stably bound keto amino sugar. The amount of such modification seen is dependent in part on the turnover rate of the protein, which explains why so much glycosylated hemoglobin occurs in normal human red cells (and more in diabetic patients).

It is very likely that the lysosomes of the characteristic Gaucher cells, and their components, do not undergo turnover at the normal rate. These lysosomes are apparently the site of accumulation of cohydrolase and of the defective enzyme's substrate, glucosyl ceramide [21]. Slow turnover of the lysosomal proteins would give them enough time to accumulate substantial amounts of sugar derivatives. Although such products are not known to bind to concanavalin A columns, the reactions could account for some of the observed chromatographic differences. The more heavily glycosylated forms might account for the diffusely trailing cohydrolase seen in gels run with the Gaucher factor.

The above hypotheses are based on the implicit assumption that posttranslational modification of cohydrolase does not occur, differentially in control and Gaucher spleen, after surgical removal from the patients. The spleens were cooled rapidly, maintained cold during homogenization, $\mathrm{pH}$ adjustment, and centrifugation, then exposed to heat only during rapid heating (and denaturation of proteinases and glycosidases) in boiling water.

Further clarification of these possibilities must await the isolation of larger amounts of the activators.

\section{Acknowledgements}

This work was supported by a grant, NS-03192, from the National Institutes of Public Health. We are indebted to Gayatri Deshmukh for developing the experiments with the individual electrophoretic bands. The spleens were kindly furnished through the cooperation of Drs. David Wenger, David Tubergen, Ruth Heyn, Norman Thompson and William W. Coon. Sherrie Coleman carried out much of the rabbit immunization procedure.

\section{References}

1 Maylie, M.F., Charles, M., Cache, C. and Desnuelle, P. (1971) Biochim. Biophys. Acta 229, 286-289

2 Ho, M.W. and O'Brien, J.S. (1971) Proc. Natl. Acad. Sci. U.S.A. $68,2810-2813$

3 Ho, M.W., O'Brien, J.S., Radin, N.S. and Erickson, J.S. (1973) Biochem. J. 131, 173-176

4 Berent, S.L. and Radin, N.S. (1981) Arch. Biochem. Biophys. 208, 248-260

5 Radin, N.S. and Berent, S.L. (1982) Methods Enzymol. 83, 596-603

6 Wenger, D.A., Sattler, M. and Roth, S. (1982) Biochem. Biophys. Res. Commun. 105, 745-751

7 Wenger, D.A., Sattler, M. and Roth, S. (1981) Trans. Am. Soc. Neurochem. 12, 210

8 Berent, S.L. and Radin, N.S. (1981) Biochim. Biophys. Acta $664,572-582$

9 Ho, M.W. (1975) FEBS Lett. 53, 243-247

10 Brady, R.O. (1978) in The Metabolic Basis of Inherited Disease (Stanbury, J.B., Wyngaarden, J.B. and Fredrickson, D.S., eds.), pp. 731-746, McGraw-Hill, New York

11 Peters, S.P., Coyle, P., Coffee, C.G., Glew, R.H., Kuhlenschmidt, M.S., Rosenfeld, L. and Lee, Y.C. (1977) J. Biol. Chem. 252, 563-573

12 Radin, N.S. (1982) in Gaucher Disease: A Century of Delineation and Research (Desnick, R.J., Gatt, S. and Grabowski, G.A., eds.), pp. 357-383, Alan R. Liss, New York

13 Gabriel, O. (1971) Methods Enzymol. 22, 565-578

14 Green, M.R., Pastewka, J.V. and Peacock, A.C. (1973) Anal. Biochem. 56, 43-51

15 Peterson, G.L. (1977) Anal. Biochem. 83, 346-356

16 Lowry, O.H., Rosebrough, N.J., Farr, A.L. and Randall, R.J. (1951) J. Biol. Chem. 193, 265-275

17 Polacheck, I. and Cabib, E. (1981) Anal. Biochem. 117, 311-314

18 Groome, N.P. (1980) J. Neurochem. 35, 1409-1417

19 Bunn, H.F., McDonald, M.J. and Shapiro, R. (1980) in Red Blood Cell and Lens Metabolism (Srivastava, S.K., ed.), pp. 455-462, Elsevier/North Holland, New York

20 Urbanowski, J.C., Cohenford, M.A. and Dain, J.A. (1982) J. Biol. Chem. 257, 111-115

21 Chiao, Y.B., Chambers, J.P., Glew, R.H., Lee, R.E. and Wenger, D.A. (1978) Arch. Biochem. Biophys. 186, 42-51 